\title{
BOURDIEU 1993: UM ESTUDO DE CASO EM CONSAGRAÇÃO CIENTÍFICA*
}

\section{Loïc Wacquant}

\author{
Tradução de André Villalobos
}

* Gostaria de agradecer ao já falecido Pierre Bourdieu (com quem o projeto de publicar seu discurso na recepção da Medalha de Ouro do CNRS foi idealizado em 1997), a Jérome Bourdieu, Marie-Christine Rivière, Gabrielle Balaz e Gilles L'Hôte, do Collège de France, assim como a Delphine Thierry-Mieg, Christelle Pineau e Sophie Deswarte, do CNRS Images. Agradeço também os testemunhos de Patrick Champagne, Odile Henry, Remi Lenoir, Francine Muel-Dreyfus, Louis Pinto e Gisèle Sapiro; a assessoria editorial de Megan Comfort e Tom Medvetz, e a assessoria biblioteconômica de Sarah Brothers. Como a cronologia é essencial no caso deste artigo, listei as publicaçôes de Bourdieu em sua ordem original de publicação. Todas as traduções do francês são minhas.
O ano de 1993 marcou uma espécie de divisor de águas para Pierre Bourdieu. Um ano antes, ele publicara As regras da arte, o "seu Flaubert", uma resposta indireta ao desafio de Sartre ([1971] 1981) em $O$ idiota da família, que tomou a forma de uma sociologia histórica da revolução simbólica que produziu a invenção do olhar estético e a cristalização do cosmos literário, e ofereceu o que Bourdieu via como a organização completamente desenvolvida de seu conceito central de campo, sobre o qual havia trabalhado ao longo de três décadas (Bourdieu, [1992] 1996). ${ }^{1}$ Nosso livro An invitation to reflexive sociology [Um convite à sociologia reflexiva], fornecendo o primeiro guia analítico compreensivo e um quadro temático de suas obras, acabava de ser publicado em sete línguas (inglês original, francês, italiano, norueguês, búlgaro e catalão, com mais cinco traduções no prelo), atestando o rápido crescimento do interesse internacional por sua sociologia e a ampliação do impacto que ela produ- 
zia (Bourdieu e Wacquant, 1992). Esse impacto se tornou mais evidente pela publicação simultânea, em inglês, de uma coletânea de textos germinais de Bourdieu (1993a) sobre The field of cultural production [O campo da produção cultural] e do primeiro volume de ensaios sobre seu pensamento a aparecer nos Estados Unidos, Pierre Bourdieu: critical perspectives [Pierre Bourdieu: perspectivas críticas] (Calhoun et al., 1993), baseado em um simpósio ocorrido em Chicago, alguns anos antes, no Center for Psychosocial Studies, confirmando que os muros da cidadela norte-americana - o núcleo da "ortodoxia planetária" da sociologia (Bourdieu, [2004] 2008, p. 93) - estavam começando a ser rompidos. ${ }^{2}$

No inverno de 1993 , o projeto de equipe organizado e dirigido por Bourdieu sobre as fontes e as formas do sofrimento social na sociedade contemporânea foi finalizado com o lançamento de $A$ miséria do mundo (Bourdieu et al., [1993] 1999). O tomo de mil páginas, composto por uma série de visões panorâmicas sobre pontos de tensão na dualizante estrutura de classes da França, fez um estardalhaço imediato para muito além do círculo de leitores acadêmicos. Vendeu 100 mil exemplares durante o ano calendário e disparou debates pelas esferas acadêmica, jornalística e política, dando ensejo a adaptações teatrais e produções de artes visuais. A intenção de Bourdieu com esse livro foi a de ampliar os limites das convenções metodológicas e da escrita sociológica de modo a alcançar "uma compreensão genética e genérica" das "quase infinitas sutilezas das estratégias mobilizadas pelos agentes na condução cotidiana de sua existência” (Bourdieu, [1993] 1996, pp. 910, 903). Mas quis também exemplificar o ímpeto socrático que marca sua socioanálise (Bourdieu, 1991a), ou seja, a humildade de princípio com que aborda ações, pensamentos e sentimentos ordinários das pessoas comuns em seu esforço por forjar instrumentos para uma "maiêutica social" capaz de fornecer-lhes os meios para compreender o princípio social de suas dificuldades pessoais. ${ }^{3}$ Bourdieu desejava curto-circuitar a censura normal da ordem vigente na mídia e nos partidos, de modo a lançar aos olhos do público um novo conjunto de questôes geradas pela interação da "pobreza de condição" e da "pobreza de posição" estimuladas pela rápida diferenciação do cosmos social e pela retração do Estado do bem- estar social keynesiano. Tornou-se claro que $A$ miséria do mundo havia atingido tal objetivo quando o primeiro-ministro conservador, Édouard Balladur, aconselhou os membros de seu gabinete de governo a ler o livro de modo a sentir o pulso da nação, e isso ficou mais claro ainda quando Bourdieu foi convidado a apresentar seu diagnóstico no conceituado programa "La Marche du Siècle", no horário nobre da televisão, em diálogo com o defensor do direito à habitação, o abbé Pierre, na época a personalidade pública individual mais popular no país. ${ }^{4}$ Para amplificar essa ebuliente discussão cívica, Bourdieu quebrou sua política de longa data de limitar estritamente suas intervenções na mídia e concedeu entrevistas sobre aquele estudo a diários e semanários nacionais, como Le Monde, Libération e L'Express, e também a veículos não convencionais, como Télérama (o equivalente francês dos guias de programação de televisão), Actualités Sociales Hebdomadaires (um boletim informativo para operários e profissionais congêneres), e a várias estações de rádio públicas francesas e estrangeiras.

1993 foi também o ano em que Bourdieu sintetizou os resultados e traçou as implicaçóes de seu curso sobre o Estado, realizado sob a forma de conferências, durante três anos, no Collège de France (publicado postumamente como Bourdieu, 2012). Após décadas consumidas cautelosamente às voltas com o Leviatã, o autor de La noblesse d'État [A nobreza de Estado] (Bourdieu, [1989] 1998) havia resolvido atacá-lo a partir de múltiplos ângulos simultaneamente: teórico, histórico e empírico. Essa importante nova frente analítica foi sinalizada por uma série de artigos interconectados mapeando "A gênese e estrutura do campo burocrático" (Bourdieu, [1993] 1994) como o lugar da monopolização da violência simbólica legítima; focalizando "A fundamental ambivalência do Estado" ([1993] 1998) como veículo para promover o universal, mas também para a usurpação do universal pelos detentores de capital cultural; e traçando as consequências da capitulação da autoridade política diante das forças de mercado, com o deslocamento da proeminência, da "Esquerda" para a da "Direita", no governo das sociedades avançadas (Bourdieu, 1992). Juntos, esse curso e as publicaçôes dele derivadas reorien- 
tariam a agenda intelectual de Bourdieu em torno da questão das lutas sobre a definiçãao histórica e a implementação dos ideais democráticos, assim como o estimulariam a multiplicar e aprofundar suas incursões no debate público durante a década seguinte (Wacquant, 2005a, esp. pp. 9-13).

No decurso desse mesmo movimentado ano, Bourdieu preparou a publicação do centésimo número de Actes de la Recherche en Sciences Sociales, o periódico por ele fundado e editado desde 1975 para servir como porta-voz a uma pertinaz sociologia transdisciplinar, unindo rigor científico, reflexividade epistêmica e pertinência sociopolítica - de modo semelhante ao que, um século antes, L'Année Sociologique o fizera para os durkheimianos (Wacquant, 2005b). É difícil exagerar a centralidade das Actes na panóplia de meios de produção científica desenvolvidos por Bourdieu ao longo dos anos. ${ }^{5}$ Além de promover uma miríade de investigações empíricas baseadas na fusão entre teoria e método, a revista operava como uma oficina que experimentava, testava e levava adiante sua agenda analítica lidando com novos terrenos, fazendo experimentaçôes com modelos gráficos e técnicas estatísticas (como Análise de Correspondência Múltipla), ${ }^{6} \mathrm{e}$ buscando tópicos transversais propensos a facilitar comparação e indução. O fato de Actes de la Recherche alcançar a marca de um quarto de século teve um significado especial para Bourdieu, não só em razão do investimento pessoal de tempo e energia que havia dedicado ao periódico, mas também porque as Actes constituíam a melhor manifestação de seu empreendimento intelectual em ruptura com um meio intelectual francês obnubilado pela "visão literária (e muito parisiense) da 'criação' como um ato singular do pesquisador isolado" (Bourdieu, [2004] 2008, p. 33). ${ }^{7}$

Este número de aniversário - apresentando artigos de Carl Schorske sobre a revolta sociológica que impulsionou as composições de Gustav Mahler, de Robert Darnton sobre o papel motor dos livros na Revolução Francesa, de William Labov sobre os caminhos para reduzir o analfabetismo, de Eric Hobsbawn sobre as lógicas características do conflito étnico, e de Armatya Sen sobre os códigos morais como vetores do sucesso econômico, juntamente com um texto inédito de Erving Goff- man sobre "a comunicação de acordo com o temperamento" - reafirmou a visão internacionalista da revista assim como o compromisso do editor em apresentar o trabalho inovador de uma nova geração de pesquisadores sociais atentos ao imperativo bachelardiano da construção do objeto. O próprio Bourdieu ([1993] 1998) contribuiu para esse número emblemático por meio de um de seus mais potentes ensaios, "Sur la famille comme catégorie réalisée" [Sobre a família como categoria realizada], no qual mostra os rudimentos de um modelo geral de formação de grupos através do exercício histórico do poder simbólico no espaço social, e de um trabalho cognitivo-cum-afetivo de construção coletiva que se harmoniza nitidamente com sua teoria do Estado como a mais importante fonte de classificação eficiente (Wacquant, 2013).

$$
* * * *
$$

Em seguida veio a notícia de que Pierre Bourdieu havia sido agraciado com a Medalha de Ouro do CNRS - Centre National de la Recherche Scientifique, o mais alto prêmio da França. Criada em 1954, a medalha era concedida anualmente a "uma personalidade científica que [tivesse] feito uma contribuição notável ao dinamismo e repercussão da pesquisa”. Esse anúncio confirmou a originalidade e a relevância da sociologia de Bourdieu, e o colocou definitivamente acima de seus pares. $\mathrm{O}$ comunicado oficial do CNRS, de 15 de setembro de 1993, diz, entre outras coisas, o seguinte:

Pierre Bourdieu, professor no Collège de France, regenerou a sociologia francesa ao unir incessantemente a precisão experimental com a teoria fundada em uma ampla cultura em filosofia, antropologia e sociologia. Essa metodologia permitiu-lhe tratar, com o rigor científico, que é uma qualidade característica de suas análises, um conjunto de questôes fundamentais em ciências sociais. Suas mais importantes e mais universalmente conhecidas contribuições tratam do papel da educação e do capital cultural na reprodução das diferenças sociais e do funcionamento do consumo cultural como signo de distinção. No Centro de Sociologia da 
Educação e da Cultura, laboratório do CNRS, graças a seu altamente inovador ensino da pesquisa guiada pela interdisciplinaridade, Pierre Bourdieu preparou um grande número de acadêmicos que contribuíram para promover o renome da atual pesquisa francesa em sociologia, história, antropologia e sociolinguística. Pierre Bourdieu é autor de inúmeros artigos e de mais de trinta livros, em sua maioria traduzidos para múltiplas línguas. Alguns deles, como Os herdeiros, $A$ distinção e $A$ miséria do mundo, constituíram eventos maiores na vida intelectual e foram aclamados por amplas audiências [...]. Incansável orquestrador científico, Bourdieu veio a tornar-se um empreendedor intelectual para fundar uma escola de pensamento. Presente em todas as frentes, desfrutando de amplo renome internacional, ele agora pertence às fileiras dos grandes intelectuais da tradição europeia.

Esse prêmio instaurou certo dilema para Bourdieu, pois ele era um homem muito tímido e reservado, com personalidade profundamente antinarcisística, marcado como era pelos valores comunais da sociedade camponesa de Béarn, na qual crescera no período entre guerras (Bourdieu, [2004] 2008, pp. 84-94; [2002] 2008). Mesmo tendo ascendido a seu ápice, ele nunca se sentiu à vontade em um mundo intelectual habituado a exaltar o ego e a celebrar o aristocratismo escolástico; tinha aversão a ser posto em evidência e positivamente abominava a pompa acadêmica. ${ }^{8}$

Mais que isso, sua "relação contraditória com a instituição acadêmica, feita de rebelião e submissão" (Bourdieu, [2004] 2008, p. 128), inclinava-o a questionar a legitimidade da academia para conceder distinções: desde seus dias de estudante na École Normale Supérieure, por um século o criadouro dos principais intelectuais franceses, "a confiança pessoal ligada ao fato de sentir-me consagrado foi erodida, em seu próprio princípio, pela mais radical falta de convicção sobre a autoridade consagradora, uma espécie de mãe má, presunçosa e enganosa”. De meados dos anos de 1960 em diante, quando se recusou a inclinar-se perante a sacrossanta exigência da tese de doutorado, ele se mantivera firme em "resoluta ruptura com a presunção das coisas acadêmicas" (Idem, p. 71). Em 1981, havia seriamente considerado rejeitar a Cátedra de Sociologia, para a qual houvera sido eleito no Collège de France, a mais importante instituição de pesquisa do país, por hesitar em passar pela pompa da conferência inaugural. Bourdieu só assumiu a posição depois de haver imaginado como tornar o evento interessante e transformá-lo em um paradigma performativo para a sociologia reflexiva, dando uma "Conferência sobre a Conferência”, na qual dissecou as fontes sociais e ressaltou a arbitrariedade simbólica do próprio "rito de consagração" que estava interpretando (Bourdieu, 1982). ${ }^{9}$

Mas a dificuldade colocada pelo anúncio do CNRS foi mais profunda que uma questão de psicologia pessoal. Prêmios, palmas, títulos, troféus, tributos, recompensas e dignidades, ainda que por mérito científico, deixavam Bourdieu pouco à vontade porque, como demonstra sua sociologia dos campos de produção cultural, eles fazem parte da "economia dos bens simbólicos" que alimentam o "autoengano coletivo" por meio do qual as instituições mistificam os agentes e se perpetuam (Bourdieu, [1994] 1998, cap. 6). Eles são indicadores da alquimia social pela qual o reconhecimento gera o desconhecimento e as relaçôes de dominação são transfiguradas em relaçôes de admiração e afeição; e tanto assinalam como mascaram nós de tensão entre poderes espirituais e temporais - razão pela qual Bourdieu gostava de citar a expressão de Gustav Flaubert de que "honras trazem desonra" (Bourdieu, 1993a, p. 154). Como o teórico supremo do poder simbólico, a noção conspícua no epicentro do trabalho de sua vida, Bourdieu também era agudamente consciente de que as formas e as formalidades públicas por meio das quais as instituições sacralizam pessoas, objetos ou atos, isto é, colocam-nos "à parte e acima do mundano", para lembrar a luminosa definição de Durkheim ([1912] 1995) em As formas elementares da vida religiosa, apresentam um perigo real: elas envolvem os assim "elevados" em uma teia de expectativas coletivas, obrigações estatutárias e vínculos organizacionais que podem paralisá-los, se não neutralizá-los, debilitando assim sua força iconoclástica. ${ }^{10}$ 


\section{Figura 1}

\section{Convite para a Cerimônia da Entrega do Prêmio.}

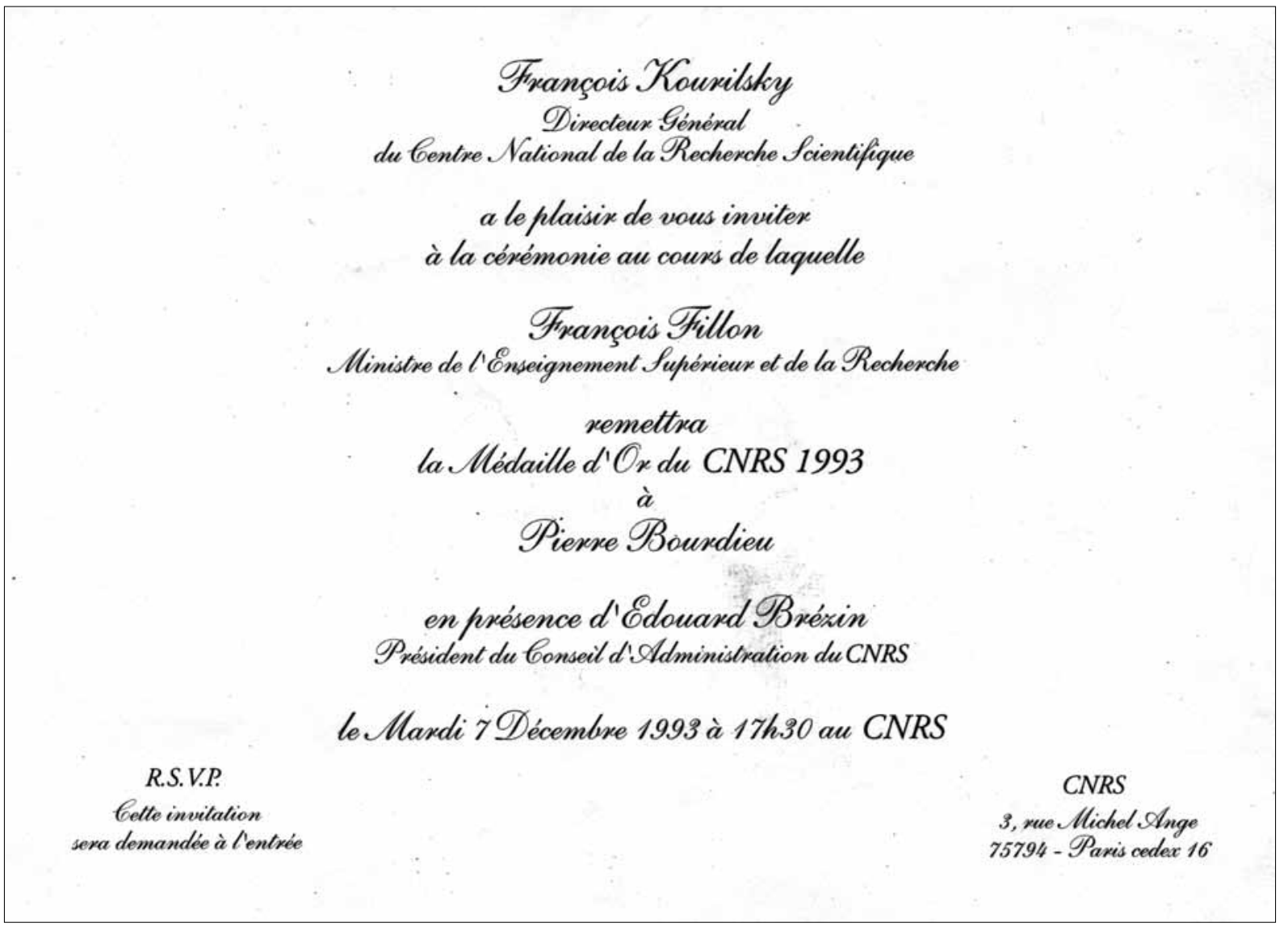

Ao mesmo tempo, outro lado de Bourdieu estava inclinado, pelo menos por uma vez, a aceitar o prêmio de 1993. E por três razôes. Em primeiro lugar, de todas as distinçōes acadêmicas, essa era a que ele considerava baseada em suas análises empíricas do mundo acadêmico francês. Em sua discussão sobre a construção estatística da estrutura do campo universitário em Homo Academicus, publicado uma década antes, Bourdieu ([1984] 1988, p. 33) sustenta que o ingresso no Institut de France e a Medalha de Ouro do CNRS constituiriam dois robustos "signos institucionalizados de prestígio acadêmico" que atestam capital especificamente intelectual, por oposição ao capital acadêmico de tipo burocrático; quando nada pelo fato de que o primeiro "consagra tanto disposiçōes ético-políticas como realizaçōes científicas" e a última, a Medalha de Ouro, é "muito excepcional" e, por isso, demasiado infrequente para servir como um indicador confiável (segundo o levantamento de 1968, apenas $1,2 \%$ de todos os acadêmicos parisienses a haviam recebido [Idem, p. 68]).

Em segundo lugar, o fato de que a medalha havia sido outorgada principalmente a cientistas naturais - incluindo uma meia dúzia de laureados com o prêmio Nobel (e dois medalhistas no campo das matemáticas [Field medalists]) -, em domínios especializados de investigação cuja independência em relação à autoridade mundana está acima de dúvida, algo que importava grandemente para Bourdieu, dado o seu compromisso de princípio e prático com a unidade epistemológica das ciências (Bourdieu, 1991b; [2001] 2004). ${ }^{11}$ Até 1993, os agraciados com a Medalha de Ouro do CNRS compreendiam 
doze físicos (incluindo quatro laureados com o Nobel), onze cientistas da vida (biologia, imunologia, fisiologia e genética, entre eles um laureado com o Nobel), seis químicos (um dos quais vencedor do Nobel), três matemáticos, assim como seis estudiosos das ciências sociais e humanidades: o geógrafo Raoul Blanchard (1960), o antropólogo Claude Lévi-Strauss (1967), o arqueólogo André Leroi-Gourhan (1973), os historiadores Jean-Pierre Vernant (1984) e Jacques LeGoff (1991) e o mentor do próprio Bourdieu (assim como professor de Foucault), o filósofo Georges Canguilhem (1987). Em terceiro lugar, e mais decisivamente, como revela essa listagem, Bourdieu seria o primeiro sociólogo a receber tal distinção, de modo que, para superar sua reticência íntima, ele poderia transformar a Medalha de uma dignidade pessoal a um tributo coletivo.

*****

Esse foi, de fato, o tema central e o propósito do discurso de Bourdieu na cerimônia de premiação: dar seu esteio científico à "disciplina pária" da sociologia, que ele havia abraçado por vontade própria em meados dos anos de 1960, após renunciar a sua estabilidade de ordem mais elevada como filósofo normalien tornado antropólogo (Bourdieu, [1987] 1990, pp. 5-8, 20-21; [1997] 2000, pp. 33-43). $\mathrm{O}$ autor de $O$ ofício de sociólogo mudou assim o foco de seus feitos individuais para as realizações coletivas do ofício, de modo a diminuir sua ansiedade pessoal e aliviar a tensão nascida de uma "espécie de antinomia entre ciência e respeitabilidade social" que existe no interior da própria ciência (Bourdieu, [1984] 1988, p. 87). Essa postura também expressava fielmente sua visão da pesquisa como uma atividade fundamentalmente coletiva, cujo verdadeiro sujeito não é o acadêmico individual, mas o campo científico in toto, isto é, a teia dinâmica de posições objetivas e de tomadas de posição subjetivas que o constituem como um espaço de intercâmbios agonísticos voltados para a produção de proposições verdadeiras por meio da estimulação mútua e de controles cruzados:

Um cientista é o campo científico feito pessoa, cujas estruturas cognitivas são homólogas às estruturas do campo e, por essa razão, constantemente ajustadas às expectativas inscritas no campo. [...] Cada ato científico é, como qualquer prática, o produto do encontro de duas histórias, a história corporificada na forma de disposiçōes e a história objetivada na própria estrutura do campo assim como em objetos técnicos (tais como instrumentos), publicaçōes etc. (Bourdieu, [2001] 2004, pp. 41, 35).

A cerimônia de entrega da medalha, em um anfiteatro repleto, com cerca de duzentas autoridades e convidados em trajes formais, incluindo os algo intimidados membros do Centre Européen de Sociologie, abriu-se com um curta-metragem (rodado especialmente para a ocasião em formato Beta SP, pelo renomado diretor Jacques Brissot) que traça um retrato caleidoscópico da persona intelectual de Bourdieu (Brissot, 1993). Os segmentos do filme captavam-no alternadamente dando uma conferência formal sobre o Estado na Universidade de Amsterdã e repreendendo os "jornalistas-filósofos" que distorcíamos padrōes de produção intelectual, ${ }^{12}$ como Jean-Marie Cavada, o âncora que é mostrado entrevistando-o durante seu "encontro de cúpula" com o abbé Pierre, e Serge July, editor-chefe do jornal de esquerda Libération, que revela ter assistido ao seminário de Bourdieu em sua juventude (muitas vezes, ouvi Bourdieu referir-se a ele como "o estudante mais tolo que jamais tive"). O curta-metragem mostra-o em diálogo com Salman Rushdie, Toni Morrison e Susan Sontag no encontro de fundação do Parlamento Internacional de Escritores, e dando uma entrevista em rádio nacional sobre a relevância cívica de $A$ miséria do mundo.$^{13}$ Mostrou também dois de seus estudantes de doutorado refletindo sobre seu estilo de orientação - eles brincam que Bourdieu se recusava a "deixá-los considerá-lo como pai", mesmo quando ele assumia o papel provocador do Doktorvater. Em cinco minutos, curtos para a audiência, mas sem dúvida intermináveis para Bourdieu, vislumbramos o autor de $A$ distinção cruzando fronteiras entre países, territórios de investigação social e cultural e domínios de conhecimento e ação.

Bourdieu foi então chamado ao palco para receber seu prêmio das mãos de François Fillon, o 


\section{Figura 2}

Ministro François Fillon com o Agraciado Pierre Bourdieu.

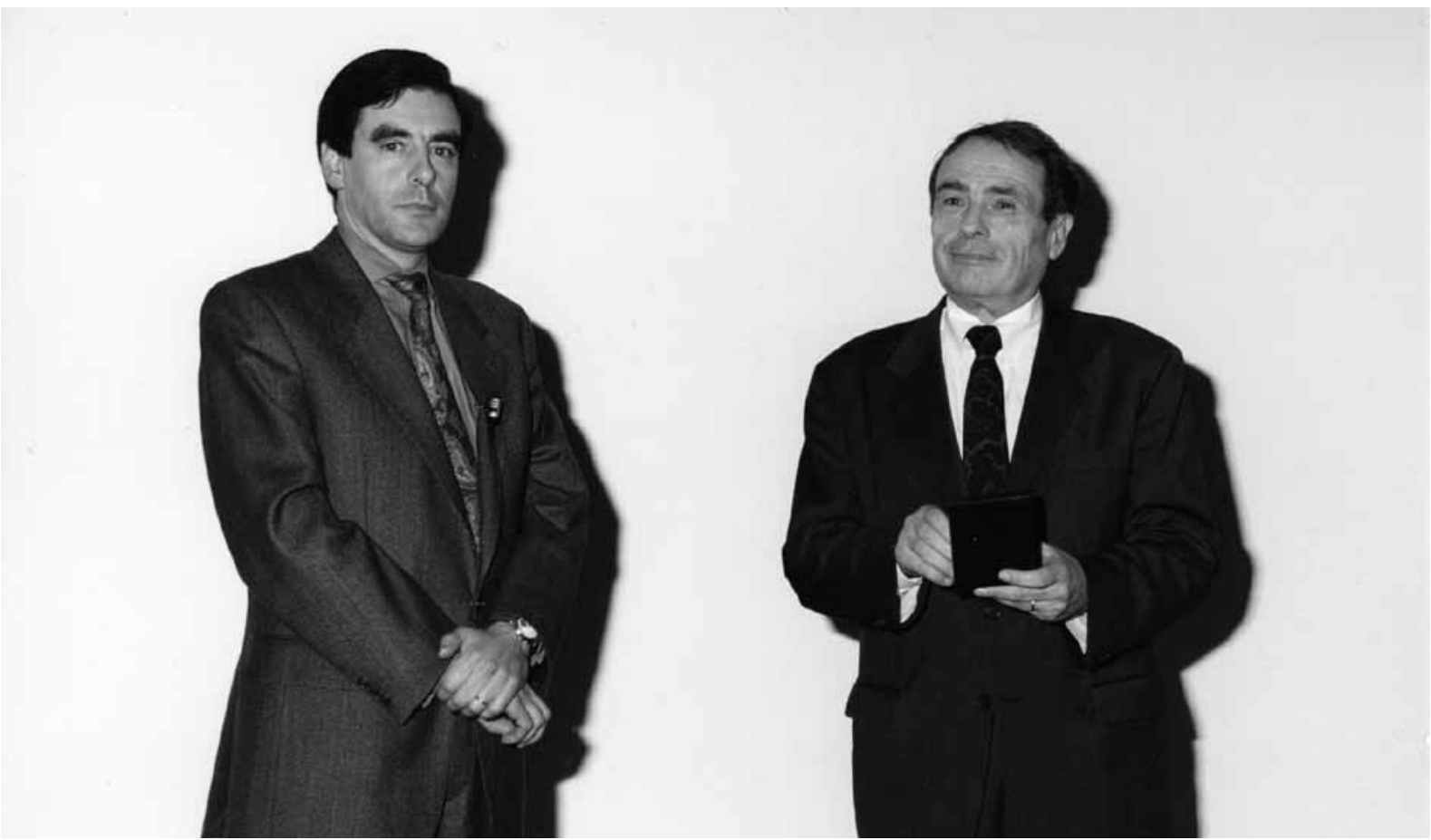

Fonte: CNRS Photothèque/Nicole TIGET.

jovem ministro para a pesquisa - que quinze anos mais tarde se tornaria Primeiro Ministro de Nicolas Sarkozy - e pronunciar seu discurso. Como uma intersecção viva entre o campo acadêmico (representado pelo presidente do CNRS), o campo político-burocrático (personificado por Fillon) e o campo jornalístico (na presença de repórteres dos principais meios de comunicação do país), ${ }^{14}$ a cerimônia proporcionou a Bourdieu uma plataforma de alto impacto para reafirmar o caráter científico do empreendimento sociológico e clamar pela defesa inflexível da autonomia do microcosmo acadêmico. Deu-lhe também a oportunidade de mais uma vez enfatizar a indispensabilidade da sociologia da sociologia como uma alavanca para escorar a estatura epistêmica da disciplina e sustentar sua independência em relação aos poderes temporais (Bourdieu, 1982, [1984] 1988, 1991b, [1997] 2000 e [2001] 2004). Ao proferir um discurso em louvor da sociologia, ele materializou, assim, a concepção sobre a "Realpolitik da razão", segundo a qual a ciência não é um transcendental kantiano, mas uma invenção histórica em processo, que avança lutando para assegurar condiçôes institucionais para a introjeção e realização de seus ideais, começando com financiamento adequado, empregos suficientes para jovens acadêmicos e proteção coletiva contra intrusões da mídia e pressões políticas. ${ }^{15}$

Em virtude do alto custo emocional que essa formalidade pública exigiu dele, Bourdieu concentrou-se em discutir criticamente a situação acadêmica e pressionar por resultados imediatos dos investimentos. E também, horresco referens, não hesitou em cometer o barbarismo social de demandar uma quota justa de posiçôes para seus estudantes e colaboradores, que há muito vinham sendo sistematicamente barrados no Centre National de la Recherche Scientifique e na École de Hautes Études en Sciences Sociales por controladores [gatekeepers] aplicados em restringir sua influência e manter um monopólio paroquial sobre os meios de reprodução acadêmica. ${ }^{16}$ Além disso, censurou 
abertamente "governos de direita e de esquerda" por gastarem mais com "pesquisas cientificamente inúteis e financeiramente ruinosas" do que com o orçamento do Collège de France (Bourdieu, 2013, p. 29). Essa intrépida investida entusiasmou o público acadêmico que o aplaudiu jubilosamente, mas chocou os dignatários da ciência e da política que ocupavam a primeira fileira. De tal maneira que o normalmente plácido Fillon sentiu-se impelido a quebrar o protocolo e voltar à tribuna para responder à acusação de Bourdieu sobre o mau uso da ciência social como um "meio de demagogia racional", num esforço contrafeito para restaurar o decoro apropriado.

Confrontando os mais altos representantes do poder político e da mídia, Bourdieu empenhou-se em reafirmar a postura da ciência social com distância calculada e vigilante contraposição a ambos. Tomando o exemplo de Max Weber ([1918] 2004), rejeitou a alternativa falsa e forçada entre o papel do profeta societário e o do especialista tecnocrata.
Contudo, com isso não desvalorizou ou restringiu o escopo da missão cívica da sociologia; pelo contrário: clamou por seu desenvolvimento como um "poder de contrabalanceamento crítico" responsável, para iluminar as possibilidades e os caminhos para a transformação social, e por um "serviço público" capaz de "exercer o papel socrático de "parteiro" [midwife] dos indivíduos e dos grupos" (Bourdieu, 2013, p. 29), isto é, capaz de forjar instrumentos bem fundamentados para a autoapropriação pessoal e coletiva -, realizando assim, de maneira concreta, a vocação tradicionalmente buscada pela filosofia. ${ }^{17}$

****

O discurso de Bourdieu na aceitação da Medalha de Ouro do CNRS e o desenrolar da cerimônia em que ele o leu, com uma voz hesitante que foi ganhando volume no cavernoso silêncio que o envolvia, apresenta um triplo interesse para a história e a sociologia da sociologia. Em primeiro lugar,

Figura 3

Bourdieu Fazendo seu Discurso.

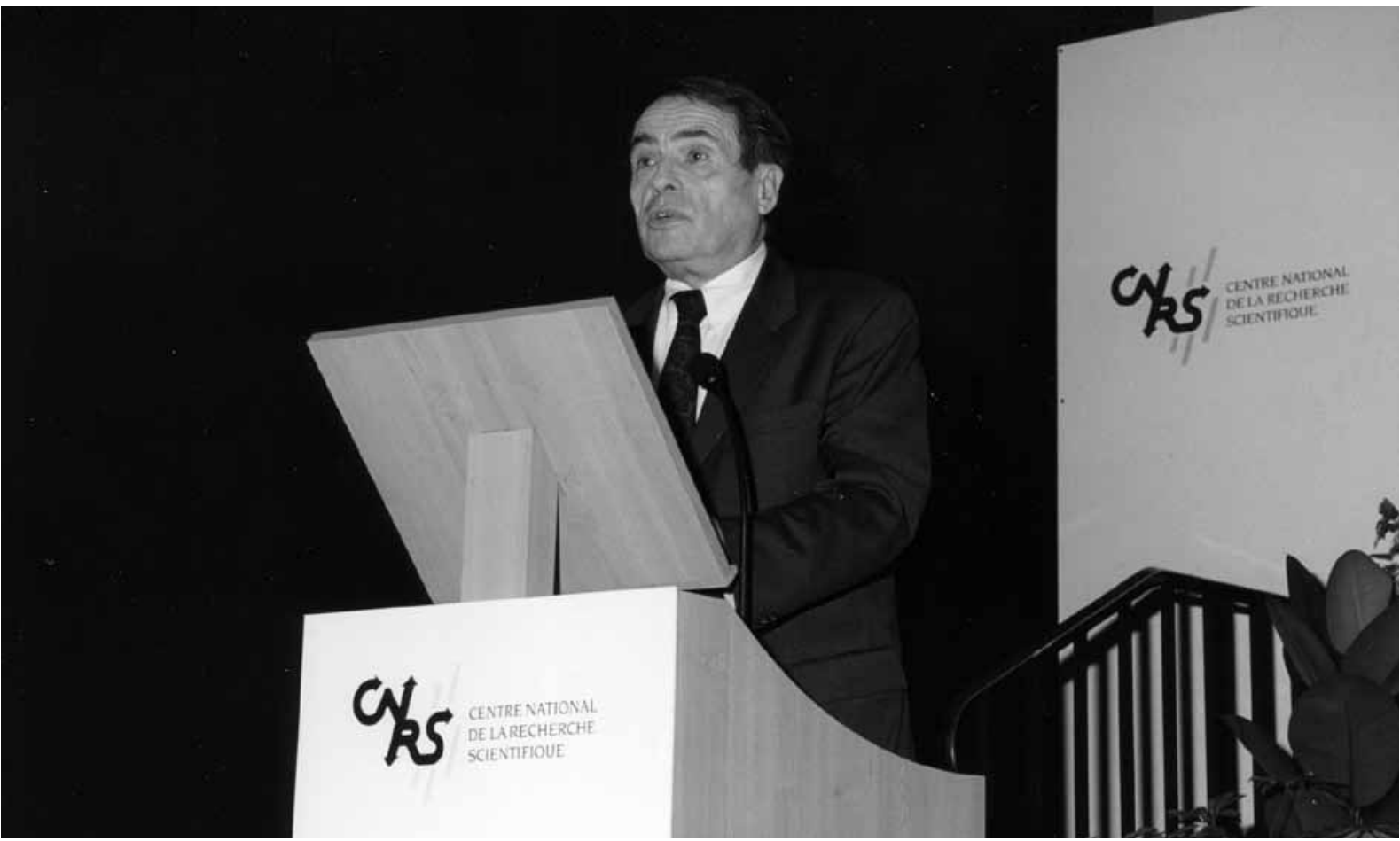

Fonte: CNRS Photothèque/Nicole TIGET. 
ilustram como Pierre Bourdieu experimentou pessoalmente, viu reflexivamente e passou em exame praticamente o nexo estreito entre ciência, autoridade e poder. Eles nos oferecem uma rara perspectiva ao rés do chão de como uma figura formadora da disciplina se ocupou concretamente da política de conhecimento, assim como nos proporcionam um estudo de caso marcante das dificuldades existenciais e das armadilhas institucionais da consagração científica. ${ }^{18}$ Em segundo lugar, marcam 1993 como um ano central na evolução intelectual de Bourdieu. Havendo consolidado seu arcabouço teórico e cumprido sua agenda de pesquisa coroada com $A$ distinção e As regras da arte, ele abriu uma nova fase de investigaçōes priorizando o funcionamento das engrenagens do Estado, o enigma da alquimia da formação de grupos e a promessa inacabada da política democrática que impulsionaria sua teoria do poder simbólico para uma nova dimensão (ver, em especial, Bourdieu, [1997] 2000, caps. 5 e 6). $\mathrm{O}$ recebimento do maior prêmio científico da França infundiu em Bourdieu a autoconfiança necessária para descartar em definitivo o estilo do sociólogo maldito e assumir inteiramente a liderança e a defesa da Cidade Sociológica. ${ }^{19} \mathrm{~A}$ premiação proporcionou-lhe também um sustentáculo suficientemente vigoroso para impeli-lo a aventurar-se mais francamente no debate público e a mobilizar seu modelo de lutas de classificação para nele intervir diretamente como uma questão de sociologia reflexiva aplicada (Bourdieu, [1998] 1999, [2000] 2003) - em vez de sublimar completamente seus impulsos políticos em sua obra científica, como tendera a fazer desde seu trabalho inicial, sobre a Argélia (Wacquant, 2004, 2005a, pp. 11-13).

Contudo, se o ano de 1993 constitui um marco na trajetória pessoal de Bourdieu e uma inflexão em seu percurso científico, é preciso voltar um século atrás para avaliar a medida adequada da importância da concessão da Medalha de Ouro em termos da história da ciência social. Em 3 de março de 1893, na Sorbonne, um jovem normalien chamado Émile Durkheim ([1893] 1997) defendeu uma arrojada tese intitulada De la division du travail social [Da divisão do trabalho social], a qual anunciou a autoafirmação de uma nova dis- ciplina e sua incipiente pretensão à supremacia sobre as abordagens literária e filosófica que até então haviam dominado o estudo da sociedade e da história. Essa defesa foi imediatamente considerada "um acontecimento" e o trabalho visto como "a pedra fundamental de um novo edifício" chamado sociologia (segundo o relatório oficial da banca examinadora, citado por Fournier, 2007, p. 188). Todavia, apenas duas décadas depois, a carnificina da Primeira Guerra Mundial dizimou os durkheimianos e arrasou esse edifício, deixando Marcel Mauss praticamente só para lutar por salvar seu legado em meio aos destroços da nação. No período entre guerras, Durkheim foi considerado "um cachorro morto" - para lembrar Marx referindo a cruel expressão de Lessing sobre Espinoza - e a filosofia rapidamente reafirmou sua primazia, com a ascensão dos "três Hs", Hegel, Husserl e Heidegger, pavimentando o caminho para dominação desimpedida da fenomenologia sartreana em meados do século XX (Descombes, 1979). Seriam necessárias outras duas décadas para que a onda estruturalista revivesse o projeto durkheimiano de uma ciência da sociedade erigida sobre "uma filosofia sem sujeito" e levasse o jovem filósofo Bourdieu para a praia sociológica (Bourdieu e Passeron, 1967). Ao aceitar a Medalha em 1993, Bourdieu enfaticamente pôs fim ao longo eclipse de Durkheim e restaurou a sociologia em seu lugar de direito no zênite científico do país de seu nascimento.

\section{Notas}

1 Até pouco antes da impressão, o título do livro fora $L e$ point de vue de l'auteur [O ponto de vista do autor], o que torna mais claro (ao contrapor o microcosmo literário à família) seu desacordo com a magna obra, em cinco volumes, de Sartre. As regras da arte foi a resposta de Bourdieu a Sartre e à sua fenomenologia (mais tarde mesclada com psicanálise e marxismo), assim como $O$ senso prático [The logic of practice] foi tanto uma homenagem a Lévi-Strauss quanto um ir além de seu estruturalismo. Aos olhos de Bourdieu ([1980] 1990, esp. pp. 1-3, 25-29), Sartre e Lévi-Strauss eram personificaçōes refinadas dos dois polos da grande antinomia entre subjetivismo e objetivismo, a qual ele se empenhou em superar. 
2 A revista French Cultural Studies também publicou um número especial sobre a obra de Bourdieu, não por coincidência aberto com uma nota pessoal de Bourdieu (1993b) sobre Sartre. Uma seleção dos principais textos de Bourdieu sobre a sociologia da política apareceu em russo (editado por Natalia Chmatko) logo em seguida a uma coleção de ensaios sobre ciência e política, em alemão, e outra sobre campos, em grego. Seguiu-se, um ano depois, um livro de diálogos com o artista Hans Haacke, vivendo em Nova York, sobre a dura relação entre a arte e o poder econômico na era neoliberal (Bourdieu e Haacke, [1994] 1995). Dois anos antes, havia sido publicado, sob o título Social theory for a changing society [Teoria social para uma sociedade em mudança] (Bourdieu e Coleman, 1991), o livro originário da conferência organizada em conjunto por Bourdieu e James Coleman, na Universidade de Chicago, em abril de 1989, para confrontar visões concorrentes a respeito dos prospectos para a sociologia mundial.

3 "Se quisesse dar à sociologia uma genealogia insigne, eu diria que, no fundo, o primeiro sociólogo foi Sócrates. Os filósofos ficariam furiosos, pois o reivindicam como um fundador [da filosofia]. Mas, na realidade, ele foi obviamente alguém que foi às ruas fazer perguntas, que foi perguntar a um general ateniense o que era a coragem, que foi perguntar a Euthyphron, um homem pio, o que era a piedade, e assim por diante. Ele estava realizando pesquisa empírica [...]. Foi alguém que combateu incansavelmente o equivalente de meus inimigos de hoje, ou ao menos aqueles a quem combato com as armas da ciência, isto é, os sofistas: pessoas que falam de um mundo irreal imaginando tratar-se do mundo real, tornando-o inalcançável ao envolvê-lo em palavras que impressionam" (Bourdieu, em Bourdieu e Chartier, 2010, p. 44).

4 Preocupado com que o choque entre a abordagem científica e a abordagem ética da desigualdade pudesse desorientar os telespectadores, Bourdieu concordou em participar, mas com considerável relutância, consentindo em fazê-lo apenas para atender ao pedido expresso de sua mãe, já idosa, que tinha veneração pelo abbé Pierre. A enervante discordância entre o sociólogo e o abade, e a irreprimível inquietação de Bourdieu, por estar naquele estúdio de televisão, são palpáveis desde a abertura do programa, quando o âncora Jean-Marie Cavada os introduziu com as seguintes palavras solenes: "Aqui estão dois homens entre os mais importantes deste final de século. Eles são diferentes e no entanto lavram o mesmo campo: o campo do sofrimento humano, o campo da pobreza" (Freine, 1993).

5 Apoiada por equipes de pesquisa acolhidas pelo Centre Européen de Sociologie (sob várias configuraçōes desde 1968), essa panóplia incluiu a série de livros "Le sens commun" publicada pela editora de vanguarda Editions de Minuit (de 1964 a 1991, seguida pela série "Liber" publicada pelas Editions du Seuil após 1992) e a Revue Européenne des Livres, publicada trimestralmente como suplemento de jornais em diversas línguas e países (de 1989 a 1998). Essa panóplia foi ampliada em 1995 com a criação da editora Raisons d'Agir, que publica pequenos e vigorosos tomos de sociologia produzidos com vistas a reestruturar para o debate cívico questōes sociopolíticas importantes (o próprio livro de Bourdieu, Sobre a televisão (On television, [1996] 1998, serviu para lançar o empreendimento), assim como monografias especializadas de ciências sociais orientadas numa linha epistemológica bachelardiana (como a de Bourdieu (2001), Science de la science et réflexivité [Para uma sociologia da ciência]).

6 A inovação estatística foi central para os avanços das teorias de Bourdieu sobre espaço social, classe e campos, como mostra Lebaron (2009), e esses avanços foram tipicamente introduzidos e refinados nas Actes.

7 Encrevé e Lagrave (2003) reúnem uma rica seleção de relatos sobre "trabalhar com Bourdieu" feitos por uma série de pesquisadores que ele treinou, com os quais colaborou e aos quais influenciou de perto e de longe na École de Hautes Études en Sciences Sociales. Os capítulos escritos por Luc Boltanski, Robert Castel, Francine Muel-Dreyfus, Jean-Claude Passeron, Michel Pialoux, Monique de Saint-Martin e Gisèle Sapiro, antigos e atuais membros do Centre Européen de Sociologie, são particularmente instrutivos com respeito aos estímulos e tensões que animavam o agitado cogitamus sociológico formado em torno de Bourdieu ao longo de anos.

8 Esses traços aparecem em várias passagens do documentário $A$ sociologia é um esporte de combate, feito por Pierre Carles (2001) sobre o trabalho de Bourdieu. Isso foi confirmado em uma entrevista para a estação nacional de rádio France Inter, concedida poucos dias antes da entrega da medalha, entrevista na qual Bourdieu confessou modestamente: "Quando fui informado de que me fora concedida a Medalha, fiquei satisfeito, mas pensei imediatamente no suplício que seria a cerimônia [...]. É verdade que, se eu pudesse recebê-la sem a cerimônia, eu ficaria muito mais feliz. Mas é assim que a coisa é, faz parte das obrigaçôes sociais que você cria". 
9 Mesmo nessas circunstâncias, a cerimônia flertou com o desastre: Bourdieu chegou perto de recolher seus papéis e abandonar o "grupo de mestres reunidos", em meio à sua conferência, ao compreender que, ao realizá-la, aquilo que para ele era "uma solução psicológica constituía um ato de provocação em relação à ordem simbólica, uma afronta à dignidade da instituição, a qual exige silêncio sobre a arbitrariedade do rito em execução" (Bourdieu, [2004] 2008, pp. 109-110). Eu me encontrava na sala aberta ao público na qual a conferência estava sendo transmitida em circuito fechado de televisão, e lembro-me vividamente desse momento: Bourdieu olhou desajeitadamente para o chão, empalideceu, e pareceu como se estivesse para precipitar-se para fora do palco. Antes do evento, ele passara por meses de insônia e, na tarde do dia da cerimônia, estava tão aturdido que "se perdeu" nas ruas de Paris a caminho do Collège.

10 Em Homo academicus, Bourdieu ([1984] 1988, pp. xxii-xvi e 105-112) discute longamente o posicionamento institucional genérico e os dilemas estratégicos específicos dos "heréticos consagrados" no campo universitário.

11 Dois laureados com o Nobel em Física, Pierre-Gilles de Gennes (1991, Medalha de Ouro do CNRS em 1980) e Claude Cohen-Tannoudji (1997, Medalha de Ouro do CNRS em 1996), foram estudantes contemporâneos de Bourdieu na École Normale Supérieure durante o período entre 1951 e 1954 (De Gennes estava na mesma turma de Bourdieu, e Tannoudji ingressou na École durante o terceiro ano de Bourdieu naquele estabelecimento), assim como colegas no Collège de France. Bourdieu ([2001] 2004, pp. 4344) esboça os princípios de suas diferentes trajetórias sociais e científicas em Para uma sociologia da ciência.

12 As raízes institucionais e os efeitos perniciosos da centralidade da filosofia e do "jornalismo filosófico" no campo intelectual francês são analisados por Bourdieu ([1984] 1988, pp. 256-270) e Pinto (2007). Uma de suas repercussões transnacionais é a volumosa exportação e o perene sucesso social da teoria literário-filosófica francesa nas universidades de língua inglesa, dissecado por Bourdieu (1997) em seu deliciosamente irônico "Passport to Duke" [Passaporte para Duke].

13 Em seguida, a uma série de assassinatos de escritores argelinos, culminando com o assassinato de Tahar Djaout por um comando em julho de 1993, cerca de sessenta intelectuais mobilizaram-se sob a liderança de Bourdieu para criar uma organização internacional dedicada a denunciar a censura e fornecer apoio material a escritores perseguidos em todo o mundo (começando com a formação de uma rede de "cidades para refugiados", em favor da qual, mais tarde, Bourdieu testemunhou perante o Parlamento Europeu). Foi, assim, em setembro de 1993, formado o Parlamento Internacional de Escritores (dissolvido em 2004), cujo comitê executivo era formado por Pierre Bourdieu, Jacques Derrida, Édouard Glissant, Salman Rushdie e Christian Salmon. Esse organismo editou um periódico intitulado Autodafé, publicado em cinco línguas, e foi particularmente ativo em torno de questôes argelinas, bósnias e palestinas. Ver Bourdieu (1994) para um relato abreviado de seus propósitos.

14 Entre outros relatos jornalísticos, Le Monde publicou uma entrevista de página inteira com Bourdieu (1993c), sobre a outorga da medalha, centrando-se em seu chamamento para "inventar um intelectual coletivo no modelo dos Enciclopedistas" para o século atual; o diário comunista L'Humanité publicou, também em página inteira, um excerto do discurso sob o título "Uma ciência não amada". Uma extensa análise das relaçóes entrelaçadas entre os campos político, jornalístico e das ciências sociais, encontra-se em Bourdieu ([1996] 2005).

15 Sintomer (2006) oferece uma estimulante discussão sobre a dialética do "corporativismo do universal" e da "Realpolitik da razão" na obra e no ativismo intelectual de Bourdieu.

16 Por ocasião da cerimônia da Medalha, em muitos anos nem um único jovem pesquisador treinado no Centre Européen de Sociologie havia sido admitido no CNRS. Após a premiação, as portas foram gradualmente abertas para os melhores orientandos de Bourdieu.

17 "A sociologia liberta ao libertar-nos da ilusão de liberdade, ou, mais precisamente, da mal fundada crença em liberdades ilusórias. A liberdade não é um dado, mas uma conquista, e, ademais, uma conquista coletiva. E lamento que, em nome de uma mesquinha libido narcisista, estimulada por uma denegação imatura das realidades, as pessoas sejam privadas de um instrumento que pode possibilitar-lhes constituírem-se verdadeiramente - um pouco mais, pelo menos - em sujeitos livres, a custo de um trabalho de reapropriação" (Bourdieu, [1987] 1990, pp. 15-16). Este tema é epicentral em $A$ miséria do mundo (ver, por exemplo, Bourdieu et al., [1993] 1998, pp. 627-629), sendo também expresso, mais concisamente, no tributo fúnebre de Bourdieu ([1998] 2004) ao etnólogo e poeta argelino Mouloud Mammeri. 
18 Esse episódio revela também a relação bifurcada de Bourdieu com o mundo social, simultaneamente lúcida e trabalhada, que se tornou ao mesmo tempo possível e mais penosa em virtude de sua penetração sociológica nesse mundo.

19 Durante décadas, Bourdieu trabalhara assoberbado pela apreensão de que nunca poderia comunicar sua visão sociológica e explicar adequadamente as implicaçóes de suas teorias: "Fui afortunado o bastante para viver por longo tempo com grande indiferença em relação ao sucesso. Lembro-me de haver pensado muitas vezes que, à medida que me empenhava para juntar competências e intençôes, teóricas e técnicas, que raramente se encontravam associadas, era provável e normal que eu permanecesse por muito tempo incompreendido e desconhecido" (Bourdieu, [2004] 2008, p. 70).

\section{BIBLIOGRAFIA}

BOURDIEU, Pierre. ([1980] 1990), The logic of practice. Cambridge, UK, Polity Press [ed. bras.: O senso prático. Petrópolis, Vozes, 2009]. . (1982), Leçon sur la leçon. Paris, Minuit. Traduzido para o inglês como "A Lecture on the Lecture," in In other wor$d s$, Cambridge, UK, Polity Press, rev. edition 1994, pp. 178-198 [ed. bras.: Liçôes da Aula. São Paulo, Ática, 1994].

([1984] 1988), Homo academicus.

Cambridge, UK, Polity Press [ed. bras.: Homo academicus. Florianópolis, UFSC, 2011]. ([1987] 1990), In other words: essays toward a reflexive sociology. Cambridge, UK, Polity Press, rev. edition 1994 [ed. bras.: Coisas ditas. São Paulo, Brasiliense, 1990]. . ([1989] 1998). The State Nobility: Elite Schools In The Field Of Power. Cambridge, UK, Polity Press.

. (1991A), "Introduction à la socioanalyse." Actes de la Rcherche en Sciences Sociales, 90: 3-5.

. (1991B), "The peculiar history of scientific reason”. Sociological Forum, 6 (1): 3-26.

. (1992), "La main gauche et la main droite de l'État”. Lignes - Revue Trimestrielle:
Arts-Littérature-Philosophie-Politique, 15: 3644 (republicado in Acts of resistance).

. ([1992] 1996), The rules of art: genesis and structure of the literary field. Cambridge, UK, Polity Press [ed. port.: As regras da arte: gênese e estrutura do campo literário. Lisboa, Presença, 1996; ed. bras.: São Paulo, Companhia das Letras, 1996].

(1993A), The field of cultural production. Nova York, Columbia University Press. . (1993B), “À propos de Sartre”. French Cultural Studies, 4: 209-211.

. (1993C), "Il faudrait réinventer une sorte d'intellectuel collectif sur le modèle des Encyclopédistes" (entrevista com Franck Nouchi). Le Monde, $7 \mathrm{dez}$.

. ([1993] 1994), "Rethinking the State: on the genesis and structure of the bureaucratic field”. Sociological Theory, 12 (1): 1-19 [publicado in Razóes práticas. Campinas, Papirus, 1996].

([1993] 1996), "Understanding". Theory, Culture, and Society, 13 (2): 13-37 [publicado in A miséria do mundo. Petrópolis, Vozes, 2003].

([1993] 1998), "On the fundamental ambivalence of the State". Polygraph, 10: 21-32.

(1994), "Un Parlement des écrivains pour quoi faire?”. Libération, 3 nov.

. ([1994] 1996), "The family as realized category”. Theory, Culture \& Society, 13 (3): 19-26 (versão resumida republicada in Practical reasons, pp. 64-74).

([1994] 1998), Practical reasons: on the theory of action. Cambridge, UK, Polity Press [ed. bras.: Razóes práticas: sobre a teoria da ação. Campinas, Papirus, 1996].

. ([1996] 1998), On television and journalism. Cambridge, UK, Polity Press [ed. port.: Sobre a televisão. Oeiras, Celta, 1997; ed. bras.: Rio de Janeiro, Zahar, 1997].

. ([1996] 2005), "The political field, the field of the social sciences, and the journalistic field", in Rodney Benson e Erik Neveu (orgs.), Bourdieu and the journalistic field, Cambridge, UK, Polity Press, pp. 29-47. 
(1997), "Passport to Duke". Metaphilosophy, 28 (4): 449-455.

. ([1997] 2000), Pascalian meditations. Cambridge, UK, Polity Press [ed. bras.: Meditaçôes pascalianas. Rio de Janeiro, Bertrand Brasil, 2001].

([1998] 1999), Acts of resistance: against the tyranny of the market. Londres, Pluto Press [ed. bras.: Contrafogos: táticas para enfrentar a invasão neoliberal. Rio de Janeiro: Jorge Zahar, 1998].

([1998] 2004), "The odyssey of reappropriation”. Ethnography, 5 (4): 617-621.

([2000] 2003), Firing back: against the tyranny of the market 2. Nova York, New Press [ed. bras.: Contrafogos 2: por um movimento social europeu. Rio de Janeiro, Jorge Zahar, 2001].

([2001] 2004), Science of science and reflexivity. Chicago, University of Chicago Press [ed. port.: Para uma sociologia da ciência. Lisboa, Edições 70, 2004; ed. bras.: São Paulo, Companhia das Letras, 2005].

([2002] 2008). The Bachelors' ball: the crisis of peasant society in béarn. Chicago, University of Chicago Press [ed. fr.: Le bal des célibataires: crise de la société paysanne en Béarn. Paris, Seuil, 2002].

([2004] 2008), Sketch for a self-analysis. Chicago, University of Chicago Press [ed. port.: Esboço para uma autoanálise. Lisboa, Edições 70, 2004; ed. bras.: Esboço de auto-análise. São Paulo, Companhia das Letras, 2005].

. (2012), Sur l'État: cours au Collège de France, 1989-1992. Paris, Seuil/Raisons d'Agir. . (2013), "Elogio da sociologia: discurso de aceitação da medalha de ouro do CNRS". Revista Brasileira de Ciências, 28(83):25-31 Sociais,

BOURDIEU, Pierre et al. ([1993] 1999), The weight of the world: social suffering in contemporary society. Cambridge, UK, Polity Press [ed. bras.: A miséria do mundo. Petrópolis, Vozes, 2003].

BOURDIEU, Pierre \& CHARTIER, Roger. (2010), Le sociologue et l'historien. Paris, La Dispute.

BOURDIEU, Pierre \& COLEMAN, James S. (eds.). (1991), Social theory for a changing society. Boulder, CO, Westview.
BOURDIEU, Pierre \& HAACKE, Hans. ([1994] 1995), Free exchange. Cambridge, UK, Polity Press.

BOURDIEU, Pierre \& PASSERON, Jean-Claude. (1967), "Sociology and philosophy in France since 1945: death and resurrection of a philosophy without subject”. Social Research, 34 (1): 162-212.

BOURDIEU, Pierre \& WACQUANT, Loïc. (1992), An invitation to reflexive sociology. Chicago/Cambridge, University of Chicago Press/ Polity Press.

BRISSOT, Jacques. (1993), Portrait de Pierre Bourdieu. Paris, CNRS Images/Femis (filmado em Beta SP).

CALHOUN, Craig J.; LIPUMA, Edward \& POSTONE, Moishe (orgs.). Pierre Bourdieu: critical perspectives. Chicago, University of Chicago Press.

CARLES, Pierre. (2001), La sociologie est un sport de combat. Montpellier, CP Productions. (Sociology is a martial art; ver a versão revista em língua inglesa no DVD francês ampliado de 2007).

DESCOMBES, Vincent. (1979), Le même et l'autre: quarante-cinq ans de philosophie française (1933-1978). Paris, Minuit.

DURKHEIM, Émile. ([1893] 1997), The division of labor in society. Trad. de W. D. Halls. Nova York, Free Press [ed. bras.: Da divisão do trabalho social. São Paulo, Martins Fontes, 2010]. . ([1912] 1995), The elementary forms of religious life. Trad. de K. E. Fields. Nova York, Free Press [ed. bras.: As formas elementares da vida religiosa. São Paulo, Martins Fontes, 2000].

ENCREVÉ, Pierre \& LAGRAVE, Rose-Marie (eds.). (2003), Travailler avec Bourdieu. Paris, Flammarion/Champs.

FOURNIER, Marcel. (2007), Émile Durkheim, 1858-1917. Paris, Fayard.

FREINE, Simon. (1993), "Souffrances d'en France: entretiens sur la situation sociale en France avec l'Abbé Pierre et Pierre Bourdieu". La marche du siècle, France 3, 14 avril (disponível em Vídeo VHS Video, France3 Diffusion, 1h28). 
LEBARON, Frédéric. (2009), "How Bourdieu 'quantified' Bourdieu: the geometric modelling of data", in Karen Robson e Chris Sanders (orgs.), Quantifying theory: Pierre Bourdieu, Berlin, Springer, pp. 11-29.

PINTO, Louis. (2007), La vocation et le métier de philosophe: pour une sociologie de la philosophie dans la France contemporaine. Paris, Seuil.

SARTRE, Jean-Paul. ([1971] 1981), The family idiot: Gustave Flaubert, 1821-1857. Chicago, University of Chicago Press.

SINTOMER, Yves. (2006), "La critique intellectuelle entre corporatisme de l'universel et espace public", in Hans-Peter Müller e Yves Sintomer (orgs.), Pierre Bourdieu: théorie et pratique, perspectives franco-allemandes, Paris, La Découverte, pp. 207-222 [em parte traduzido para o inglês como "Intellectual critique and the public sphere", in Simon Susen e Bryan S. Turner (orgs.), The legacy of Pierre Bourdieu: critical essays, Londres/Nova York, Anthem Press, 2011, pp. 329-346].

WACQUANT, Loïc. (2004), "Following Pierre Bourdieu into the field". Ethnography, 5 (4): 387-414 [em port.: "Seguindo Pierre Bourdieu no terreno", Cadernos de Ciências Sociais, Lisboa, número especial sobre "Génese e legado da obra de Pierre Bourdieu”, 24: 69-96; também publicado como "Seguindo Pierre Bourdieu no campo", Revista de Sociologia e Política, número especial sobre "Bourdieu no campo", 26 (2), 2006, pp. 13-29]. . (org.). (2005A), Pierre Bourdieu and democratic politics: the mystery of ministry. Cambridge, UK, Polity Press [ed. bras.: O mistério do ministério: Pierre Bourdieu e a política democrática. Rio de Janeiro, Revan, 2005].

(2005B), "A sociological workshop in action: Actes de la Recherche en Sciences Sociales", in Lawrence D. Kritzman (org.), The Columbia history of Twentieth-Century French thought, Nova York, Columbia University Press, pp. 683-685 [versão em português: "Uma oficina sociológica em ação: Actes de la Recherche en Sciences Socials". Revista de Sociologia e Politica, 19: 104-110, 2002.].
(2013), "Symbolic power and group-making: on Bourdieu's reframing of class”. Journal of Classical Sociology, 13 (2): 274-291 [versão em português: "Poder simbólico e fabricação de grupos: como Bourdieu reformula a questão das classes". Novos Estudos Cebrap, 96: 87-103].

WEBER, Max. ([1918] 2004), The vocation lectures: science as a vocation, politics as a vocation. Indianapolis, Hackett [ed. bras.: Ciência e política: duas vocaçôes. São Paulo, M. Claret, 2002]. 


\section{BOURDIEU 1993: UM ESTUDO DE CASO EM CONSAGRAÇÃO CIENTÍFICA}

\section{Loïc Wacquant}

Palavras-chave: Bourdieu; Consagração; Capital intelectual; Academia francesa; História da Sociologia.

Por meio de testemunhos e de documentos de arquivo, proponho uma reconstituição das condiçôes em virtude das quais Bourdieu recebeu, em 1993, a medalha de ouro do Centre National de la Recherche Scientifique, a mais alta distinção científica na França, em reconhecimento ao estudo sobre a situação existencial e as armadilhas institucionais da consagração acadêmica. $\mathrm{O}$ discurso proferido por Bourdieu na ocasiāo e a cerimônia na qual foi lido apresentam um triplo interesse para a história e para a sociologia da sociologia. Ilustram como uma personalidade formada pela disciplina viveu, refletiu e transitou pelas conexões entre a ciência, a autoridade e o poder. Marcam 1993 como o ano chave na evolução intelectual de Bourdieu, quando uma nova agenda de pesquisa traz para o primeiro plano o Estado como um poder simbólico primordial. Ajudam a explicar por que na década de 1990 Bourdieu se aventura de forma tão direta no debate cívico. A aceitação ambivalente desse prêmio por Bourdieu ilustra igualmente sua concepção da "Realpolitik da razão" e coloca um fim ao eclipse de Durkheim ao restaurar à Sociologia seu lugar de direito no zênite científico de seu país natal.

\section{BOURDIEU 1993: A CASE STUDY IN SCIENTIFIC CONSECRATION}

Loïc Wacquant

Keywords: Bourdieu; Consecration; Intellectual capital; French academy; History of sociology.

Drawing on archival materials and personal testimonies, I reconstruct the conditions under which Bourdieu came to receive the Gold medal of the National Center for Scientific Research, France's highest science prize, in 1993 as a signal case study of the existential predicament and institutional trappings of scholarly consecration. Bourdieu's award speech and the ceremony at which he read it present a triple interest for the history and sociology of sociology. They illustrate how a shaping figure in the discipline personally experienced, reflexively viewed, and practically navigated the nexus of science, authority, and power. They mark 1993 as a pivot-year in Bourdieu's intellectual evolution, leading to a new agenda foregrounding the state as paramount symbolic power, the alchemy of group formation, and the unfinished promise of democratic politics; and they help explain why he ventured more forthrightly into civic debate in the 1990s. Bourdieu's ambivalent acceptance of the prize also illustrates his conception of the "Realpolitik of reason" and put an emphatic end to the eclipse of Durkheim by restoring sociology to its rightful place at the scientific zenith in the country of its birth.

\section{BOURDIEU 1993: UNE ÉTUDE DE CAS EN CONSÉCRATION SCIENTIFIQUE}

\section{Loïc Wacquant}

Mots-clés: Bourdieu; Consécration; Capital intellectuel; Académie Française; Histoire de la sociologie.

Grâce à des témoignages et des documents d'archives, je propose une reconstitution des conditions en vertu desquelles Bourdieu a reçu, en 1993, la médaille d'or du Centre National de la Recherche Scientifique, la plus haute distinction scientifique en France, en reconnaissance à une étude sur la situation existentielle et les pièges institutionnels de la consécration savante. Le discours prononcé par Bourdieu à l'occasion et la cérémonie au cours de laquelle il l'a lu présentent un triple intérêt pour l'histoire et pour la sociologie de la sociologie. Ils illustrent comment une personnalité façonnée par la discipline a vécu, réfléchi et a transité par les liens entre la science, l'autorité et le pouvoir. 1993 devient une année-clé dans l'évolution intellectuelle de Bourdieu, conduisant à un nouvel agenda qui place en premier plan l'État comme un pouvoir symbolique primordial, l'alchimie de la formation de groupe et la promesse inachevée de la politique démocratique. Ils aident à expliquer pourquoi il s'aventure de façon si directe dans le débat civique des années 1990. L'acceptation ambivalente de ce prix par Bourdieu illustre également sa conception de la " Realpolitik de la raison » et met un terme à l'éclipse de Durkheim en rétablissant la sociologie à la place qui lui revient, au zénith scientifique de son pays natal. 